\title{
Frontières
}

MAURY, Marc, Le plongeon vers la vie !, Paris, Bayard, 2002, $203 \mathrm{p}$.

\section{Louise Rousseau}

Volume 16, numéro 1, automne 2003

URI : https://id.erudit.org/iderudit/1073773ar

DOI : https://doi.org/10.7202/1073773ar

Aller au sommaire du numéro

\section{Éditeur(s)}

Université du Québec à Montréal

\section{ISSN}

1180-3479 (imprimé)

1916-0976 (numérique)

Découvrir la revue

\section{Citer ce compte rendu}

Rousseau, L. (2003). Compte rendu de [MAURY, Marc, Le plongeon vers la vie !, Paris, Bayard, 2002, 203 p.] Frontières, 16(1), 100-101.

https://doi.org/10.7202/1073773ar d'utilisation que vous pouvez consulter en ligne.

https://apropos.erudit.org/fr/usagers/politique-dutilisation/ 
femme, à ses côtés depuis près de soixante ans.

Un récit autobiographique sous forme d'anecdotes, d'humour, de souvenirs. "Je n'aime dans l'Histoire que les anecdotes ", nous dit-il en citant Prosper Mérimée. Tantôt du côté du médecin, tantôt du côté du malade, l'auteur retrace l'histoire de la rééducation dont il est l'un des pionniers.

"La faculté d'adaptation de l'être humain est incommensurable. Sans doute parce qu'il ne peut pas en prévoir le prix » (p. 141).

À travers le récit, certains thèmes

MAURY, Marc

\section{Le plongeon vers la vie !}

Paris, Bayard, 2002, 203 p.

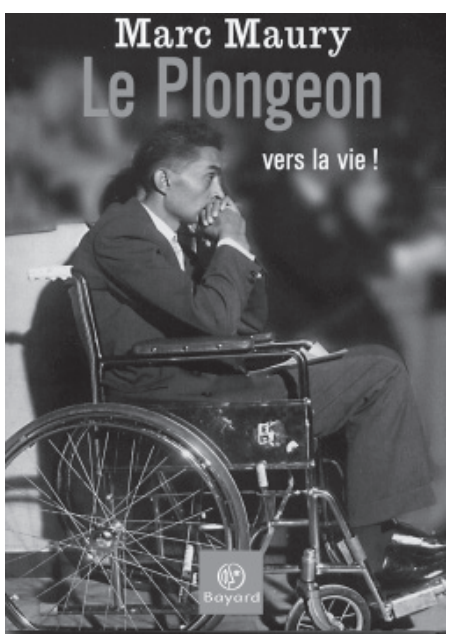

LES MÉMOIRES D'UN PIONNIER DE LA RÉÉDUCATION NEUROLOGIQUE

L'auteur, Marc Maury, a 22 ans lorsqu'il devient tétraplégique à la suite d'un plongeon imprudent. À cette époque, en 1945, les soins spécialisés et la rééducation n'existent pas; les médecins doutent même de la survie possible de cet étudiant en médecine, marié et père d'une fillette de trois mois.

Non seulement il a survécu à ce plongeon et à sa tétraplégie mais il a complété sa médecine, se déplaçant avec des cannes canadiennes ou en "vélocimane " d'un stage à l'autre. Il est nommé médecin-chef du centre de rééducation neurologique de Fontainebleau et pendant de nombreuses années, il est médecin, tétraplégique, ayant à sa charge des centaines de patients paralysés, à une époque où tout est à découvrir sur la rééducation neurologique. Actuellement octogénaire, retraité de la médecine, fréquentant maintenant les hôpitaux comme patient, il a publié ses mémoires en 2002 et, en préface, quelques mots de sa se dégagent: Comment arriver à vivre avec la paralysie? Pour y arriver, faut-il faire le deuil de la station debout, de la marche, accepter d'être assis? S'agit-il plutôt de "s'adapter" à ce qui est inacceptable ? Faut-il trouver un sens à une situation que le destin a imposée?

Comment répondre à ces questions au plan personnel, comme malade, et au plan professionnel comme médecin de patients atteints du même mal...Comment concilier la distance nécessaire au médecin et la vision de l'intérieur du malade?

Pour Marc Maury, s'adapter au handicap, s'occuper de réadaptation, a été plus concret et constructif que de parler du deuil de la marche (il nous dit avoir longtemps espéré pouvoir remarcher), mais comme médecin, il a été confronté aux réactions de ses patients et à celles des intervenants, réactions incluant le suicide (et même le suicide assisté) de certains de ses patients et l'eugénisme de certains soignants.

Un récit ponctué de propos sur l'évolution de la rééducation mais surtout de petites phrases, glissées tout au long du récit, qui font réfléchir. Surtout en ces temps de changement dans les services de santé...

"Le respect du malade, de sa personnalité comme de sa pudeur, compte autant que la qualité des soins» (p. 24).

"Le bon sens et la faculté d'écoute sont, me semble-t-il, des qualités fondamentales pour un médecin... Le bon sens est particulièrement utile pour éviter de qualifier de "psychologique" ce qu'on ne comprend pas » (p. 133).

On aurait aussi pu citer ses paragraphes sur l'écoute, la prescription de médicaments et sur le lien nécessaire entre les deux...Sans oublier le thème du respect du malade, respect du corps du patient qui a perdu le contrôle de sa mobilité, de ses sphincters, de sa sexualité.

Quatre vingts ans ou presque, plus de 55 ans de tétraplégie, une vie professionnelle consacrée à la 
rééducation, une participation à un groupe de réflexion sur l'éthique, de nombreux écrits pour les médecins, le goût d'un récit plus personnel, tout ceci donne une saveur particulière à ces mémoires, qui oscillent entre les confidences sur la maladie, le vieillissement (qui accentue le handicap) et les réalisations professionnelles comme pionnier dans I'univers de la rééducation neurologique.

Des thèmes sérieux, pourtant le résultat se lit comme un roman. L'auteur nous entraîne dans son récit, le ton de l'anecdote, et l'humour, contribuent à la légèreté du rythme et traduisent bien ce plongeon vers la vie. M. Maury choisit des mots simples pour nous faire penser, et il réussit très bien.

Louise Rousseau 